\title{
APLIKASI TRANSISTOR DARLINGTON PADA RANGKAIAN INVERTER PORTABLE
}

\author{
Sofitri Rahayu1, Jaja Kustijal2 \\ 1Sekolah Tinggi Teknik-PLN \\ 2Universitas Pendidikan Indonesia \\ E-mail: sofitri@sttpln.ac.id
}

\begin{abstract}
Electrical energy is used in every field of human life to help easy the work of man. The need for source of alternating current (AC) electrical energy is not available in any place as long as when we are far from energy supplay. For electricity to get sourcelalternating current (AC) electrical energy when they are away from the source a way to change the source of DC into AC using an inverter. Inverter is designed to be portable using 12 Volt DC source and component based inverter IC 555 as a pulse generator and CMOS 4013 as a series of D flip flop. Because the voltage is out of the CMOS 4013 is small then connected with MJ11016 transistor as an amplifier. Then the resulting voltage is increased by using a tranformator step up. This system is designed to capability the strength power 60 Watt.
\end{abstract}

Keywords: inverter, voltage, electrical energy, trafo Step Up

\begin{abstract}
ABSTRAK
Energi listrik digunakan dalam segala lapangan kehidupan manusia untuk membantu meringankan pekerjaannya. Kebutuhan akan sumber energi listrik AC (arus bolak balik) tidak selamanya tersedia di setiap tempat misalnya ketika kita berada jauh dari supplay energi listrik dari PLN. Untuk mendapatkan sumber energi listrik arus bolak balik (AC) ketika berada jauh dari sumbernya maka di dapat dengan cara mengubah sumber DC menjadi AC menggunakan inverter. Inverter yang dirancang portable menggunakan sumber DC 12 volt dan komponen inverter berbasis IC 555 sebagai pembangkit pulsa dan CMOS 4013 sebagai rangkaian D flip-flop. Karena tegangan yang keluar dari CMOS 4013 ini kecil maka dihubungkan dengan transistor MJ11016 sebagai penguat. Kemudian tegangan yang dihasilkan dinaikkan dengan menggunakan trafo Step Up. Sistem ini dirancang berkemampuan daya sebesar 60 watt.
\end{abstract}

Kata kunci: inverter, tegangan, energi listrik, trafo Step Up 


\section{PENDAHULUAN}

Penggunaan listrik saat ini sudah sangat luas. Sebagian besar peralatan kebutuhan manusia menggunakan listrik. Karena kebutuhan energi listrik yang sangat besar itu, setiap hari manusia selalu berfikir untuk menciptakan dan menggunakan energi listrik dengan efektif dan efesien. Ketika manusia berada di tempat yang tidak mempunyai persediaan energi listrik yang banyak atau bahkan tidak ditemukan energi listrik, maka perlu disiasati agar pasokan listrik terus ada sehingga aktifitas manusia bisa berjalan seperti biasanya. Sebagai contoh, ketika manusia berada dalam perjalanan jauh yang menghabiskan waktu tempuh yang sangat panjang dan pasokan energi listrik tidak terjamin. Solusi yang terbaik adalah dengan membuat suatu alat penyimpan energi listrik dalam bentuk baterai untuk kebutuhan listrik DC dan listrik AC. Maka diperlukan sumber listrik yang dapat dibawa kemana saja sesuai dengan kegiatan manusia yang selalu beraktivitas. Inverter portable bisa mengubah listrik DC menjadi AC, adalah solusi untuk membantu aktivitas manusia yang memerlukan energi listrik dimana saja.

\section{METODE/PERANCANGAN PENELITIAN}

\subsection{Inverter}

Inverter adalah alat yang berfungsi untuk mengubah dari arus searah (DC) menjadi arus bolakbalik (AC) dengan frekuensi tertentu menggunakan metode switching. Switching itu sendiri adalah proses perpindahan antara kondisi ON dan OFF ataupun sebaliknya. Pencacahan arus DC dengan proses switching ini dimaksudkan agar terbentuk gelombang AC yang dapat diterima oleh peralatan/beban listrik AC.

Komponen utama yang digunakan haruslah sangat cepat dalam proses switching sebuah inverter, sehingga tidak memungkinkan bila digunakan saklar ON-OFF, relay, kontaktor dan sejenisnya. Akhirnya dipilihlah peralatan-peralatan semi-konduktor yang mampu berfungsi sebagai saklar/ pencacah tegangan, selain itu juga mampu melakukan proses switching dalam tempo yang sangat cepat. Contoh semi-konduktor diantaranya seperti transistor, BJT, IGBT, dan sejenisnya.

Inverter adalah alat yang berfungsi untuk merubah dari tegangan DC baterai atau rangkaian rectifier-charger menjadi tegangan $\mathrm{AC}$, sinyal atau gelombang output berbentuk kotak setelah melalui pembentukan gelombang dan rangkaian filter. Amplitudo tegangan maupun frekuensi dari tegangan keluaran yang dihasilkan harus stabil.

Inverter yang digunakan secara umum ada dua macam yaitu :

- Inverter True-sinewave atau biasa dikenal dengan gelombang sinus murni. Inverter ini menghasilkan gelombang listrik yang sama dengan gelombang listrik dari PLN bahkan lebih baik dalam segi kestabilan daya listrik. Gelombang daya listrik yang dihasilkan bila dilihat dengan menggunakan osiloskop memperlihatkan gelombang sinus yang sempurna.

- Inverter Modified-sinewave atau biasa dikenal dengan gelombang sinus modifikasi. Inverter ini menghasilkan daya listrik yang cukup memadai tetapi memiliki kelemahan yaitu kekuatan daya listrik yang dihasilkan tidak sama dengan daya listrik yang dihasilkan dari PLN. Bila dilihat melalui osiloskop, bentuk gelombang yang timbul berbentuk kotak yang kaku.

Inverter juga diklasifikasikan menjadi dua macam yaitu : inverter satu fasa (inverter setengah gelombang dan inverter gelombang penuh) dan inverter tiga fasa (inverter tiga fasa dengan frekuensi, tegangan konstan dan inverter tiga fasa dengan frekuensi, tegangan berubah). 


\subsection{Rectifier}

Rectifier adalah alat yang berfungsi untuk mengubah sumber arus bolak-balik (AC) menjadi sumber arus searah (DC). Gelombang AC yang berbentuk gelombang sinus hanya dapat dilihat dengan osiloskop. Rangkaian rectifier banyak menggunakan transformator step down yang digunakan untuk menurunkan tegangan sesuai dengan perbandingan transformator yang digunakan. Rectifier dibedakan menjadi dua jenis, yaitu rectifier setengah gelombang dan rectifier gelombang penuh. Adapun penyearah yang digunakan dalam perancangan ini adalah penyearah setengah gelombang.

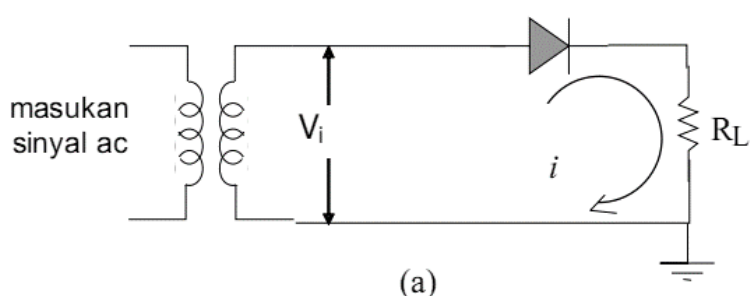

Gambar 1. Rangkaian Penyearah Setengah Gelombang

\subsection{IC 555 dan CMOS 4013}

Dalam dunia elektronika, baik analog maupun digital, IC 555 banyak dijumpai sebagai pembangkit pulsa (pulse generator) dan komponen utama pewaktu (timer). Hal ini disebabkan karena IC 555 sangat mudah dalam perancangan dan stabil saat digunakan. Secara keseluruhan IC 555 tersusun atas 2 komparator tegangan, 1 flip-flop bistable, 1 transistor pembuangan (discharge) dan 3 resistor pembagi tegangan. Fungsi-fungsi pin/kaki IC 555 seperti yang ditunjukkan pada susunan pin dan blok diagram IC 555 di bawah ini.

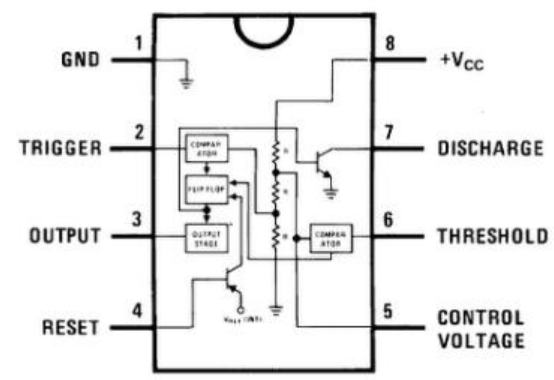

Gambar 2. Pin Diagram IC 555

Ada dua macam rangkaian dasar yang banyak digunakan untuk mengaplikasikan IC timer ini, yaitu rangkaian monostable dan rangkaian astable.

\subsubsection{Rangkaian Monostable}

Rangkaian ini didesain sedemikian rupa sehingga hanya memerlukan sedikit komponen luar untuk bekerja. Komponen luar tersebut yang utama diantaranya adalah resistor dan kapasitor luar (eksternal). IC ini bekerja dengan memanfaatkan prinsip pengisian (charging) dan pengosongan (discharging) dari kapasitor melalui resistor luar tersebut.

Lamanya pulsa yang dihasilkan, tergantung dari nilai resistor dan kapasitor eksternal yang digunakan. Dari rumus ekponensial pengisian kapasitor diketahui bahwa : 
$\mathrm{Vt}=\mathrm{VCC}(1-\mathrm{e}-\mathrm{t} / \mathrm{RC})$

Vt adalah tegangan pada saat waktu t. Jika t adalah waktu eksponensial yang diperlukan untuk mengisi kapasitor sampai $\mathrm{Vt}=2 / 3 \mathrm{VCC}$, maka rumus (1) dapat disubstitusi dengan nilai menjadi : $\ln (1 / 3)=-\mathrm{t} / \mathrm{RC}$ dan seterusnya dapat diperoleh dan $\mathrm{t}=(1.0986123) \mathrm{RC}$ yang dibulatkan menjadi 1,1 .

$$
\begin{gathered}
2 / 3=1-\mathrm{e}-\mathrm{t} / \mathrm{RC} \\
1 / 3=\mathrm{e}-\mathrm{t} / \mathrm{RC} \\
\mathrm{t}=1.1 \mathrm{RC}
\end{gathered}
$$

Inilah rumusan untuk menghitung lamanya keluaran pulsa tunggal yang dapat dihasilkan dengan rangkaian monostable dari IC 555.

\subsubsection{Rangkaian Astable}

Rangkaian astable dibuat dengan mengubah susunan resistor dan kapasitor luar pada IC 555 seperti gambar 3 ada dua buah resistor $\mathrm{Ra}$ dan $\mathrm{Rb}$ serta satu kapasitor eksternal $\mathrm{C}$ yang diperlukan. Pada prinsipnya, rangkaian astable dibuat untuk memicu dirinya sendiri berulang-ulang sehingga rangkaian ini dapat menghasilkan sinyal osilasi pada keluarannya. Ketika power supply pada rangkaian ini di nyalakan, kapasitor $\mathrm{C}$ mulai terisi melalui resistor $\mathrm{Ra}$ dan $\mathrm{Rb}$ sampai mencapai tegangan $2 / 3 \mathrm{VCC}$.

Inilah batasan untuk mengetahui lebar pulsa dari periode osilasi yang dihasilkan. Misal diasumsikan $\mathrm{t} 1$ adalah waktu proses pengisian kapasitor yang diisi melalui resistor $\mathrm{Ra}$ dan $\mathrm{Rb}$ dari 1/3 VCC sampai 2/3 VCC. Diasumsikan juga t2 adalah waktu discharging kapasitor melalui resistor Rb dari tegangan 2/3 VCC menjadi 1/3 VCC. Dengan perhitungan eksponensial dengan batasan $1 / 3$ VCC dan 2/3 VCC maka dapat diperoleh :

$$
\begin{aligned}
\mathrm{t} 1 & =\ln (2)(\mathrm{Ra}+\mathrm{Rb}) \mathrm{C}=0.693(\mathrm{Ra}+\mathrm{Rb}) \mathrm{C} \\
\mathrm{t} 2 & =\ln (2) \mathrm{RbC}=0.693 \mathrm{RbC} \\
\mathrm{T} & =0.693((\mathrm{Ra}+2 \mathrm{Rb}) \mathrm{C}) \\
\mathrm{F} & =1 / \mathrm{T}=1.44 /\left(\mathrm{R} \_\mathrm{a}+\llbracket 2 \mathrm{R} \rrbracket \_(\mathrm{b})\right) \mathrm{C}
\end{aligned}
$$

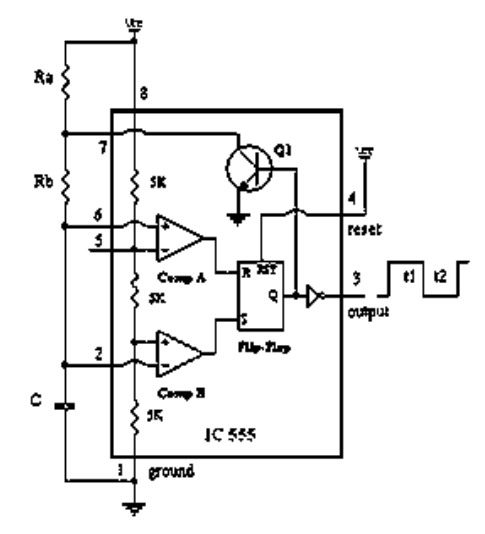

Gambar 3. Rangkaian Astable 
Periode osilator dapat dihitung dengan menggunakan rumus $\mathrm{T}=\mathrm{t} 1+\mathrm{t} 2$. Presentasi duty cycle dari sinyal osilasi yang dihasilkan dapat diketahui dengan menghitung t1/T. maka untuk medapatkan duty cycle osilator sebesar (mendekati) $50 \%$, maka dapat digunakan resistor Ra yang relatif jauh lebih kecil dari resistor $\mathrm{Rb}$.

\subsection{CMOS 4013}

Pemicu transistor output daya untuk menghasilkan sinyal persegi disini menggunakan drive flip-flop tipe CMOS 4013. CMOS 4013 termasuk D flip-flop jenis ini secara normal dalam keadaan mode memori baik clok pada logik 0 maupun pada logik 1 . Hanya ada satu interval waktu yang sangat pendek yang dapat mengubah keadaan keluaran, yaitu masa perubahan dari 0 ke 1 , atau perubahan dari $1 \mathrm{ke}$ 0. Flip flop jenis ini hanya merespon pada sisi naik atau sisi turun dari sebuah bentuk gelombang masukan, selain itu D flip flop selalu dalam keadaan mode memori. Simbol dan tabel kebenaran D flip-flop dapat dilihat seperti pada gambar 4.

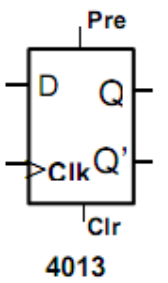

\begin{tabular}{|r|c|c|c|l|}
\hline \multicolumn{5}{|c|}{ Tabel kebenaran } \\
\hline $\mathbf{D}$ & Clk & $\mathbf{Q}^{\prime}$ & $\mathbf{Q}^{\prime}$ & Mode \\
\hline $\mathrm{X}$ & 0 & $\mathbf{Q}_{\mathrm{t}}$ & $\mathrm{Q}_{\mathrm{t}}^{\prime}$ & Memory \\
\hline $\mathrm{X}$ & 1 & $\mathrm{Q}_{\mathrm{t}}$ & $\mathrm{Q}_{\mathrm{t}}$ & Memory \\
\hline 0 & 8 & 0 & 1 & Data in \\
\hline 8 & 8 & 1 & 0 & Data in \\
\hline
\end{tabular}

Gambar 4. Simbol dan Tabel D flip-flop

\section{HASIL DAN PEMBAHASAN}

\subsection{Rangkaian Inverter}

Sistem inverter ini merupakan perubahan tegangan DC ke AC, yaitu dari baterai yang bertegangan $12 \mathrm{~V}$ yang memberi input tegangan untuk inverter. Kemudian tegangan output dari inverter dinaikkan menggunkan trafo step up yang tegangan menghasilkan tegangan AC. Untuk jelasnya berikut ini disajikan blok diagram sistemnya.

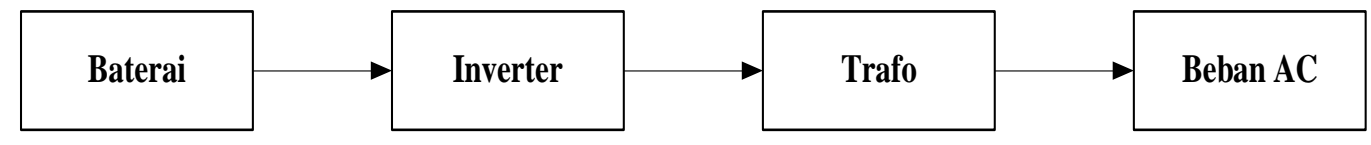

Gambar 5. Blok Diagram Inverter

Rangkaian inverter pada gambar dibawah berfungsi untuk merubah tegangan yang diberikan baterai DC menjadi AC dengan menggunakan IC timer 555. IC 555 timer dikonfigurasi sebagai multivibrator yang dapat disesuaikan secara akurat dengan alat potensiometer. Secara keseluruhan IC 555 tersusun atas 2 komparator tegangan, 1 flip-flop bistable, 1 transistor pembuangan (discharge), dan 3 resistor pembagi tegangan. 


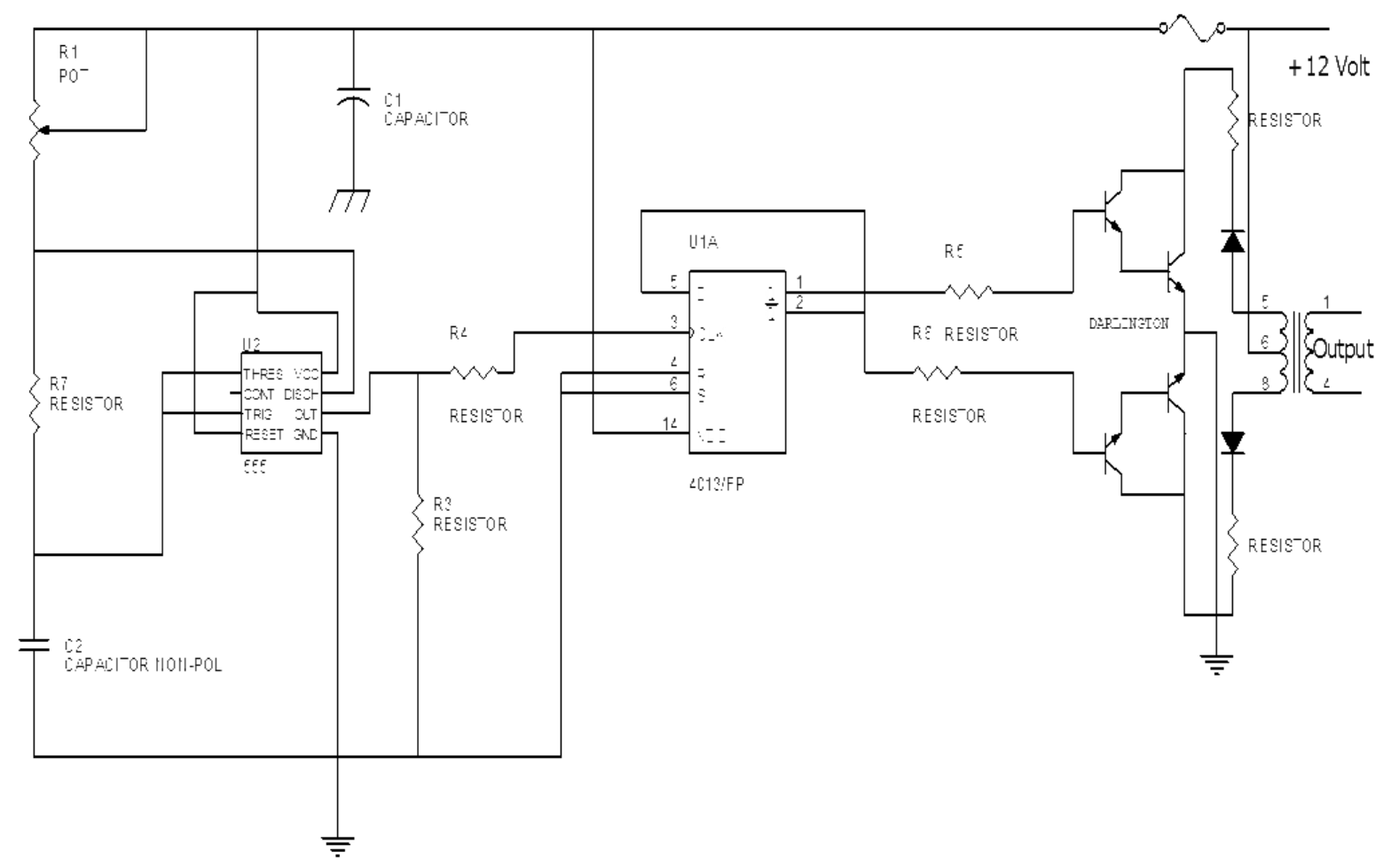

Gambar 6. Rangkaian Inverter

Sedangkan untuk drive flip-flop menggunakan tipe CMOS 4013 yang menghasilkan sinyal persegi untuk memicu transistor output daya. Karena arus keluaran yang tersedia dari CMOS 4013 sangat kecil maka transistor darlington yang digunakan untuk memenuhi keluaran yang diperlukan maka dipilih jenis semi konduktor MJ power darlington yang setara dapat digunakan.



Gambar 7. Rangkaian Pewaktu Monostable

Transistor darlington dipasang terpisah ke sebuah heat sink alumunium anodize - bersirip menggunakan aksesori standar isolasi mika. Jadi kabel yang menghubungkan kolektor dari MJ ke primer trafo, emitter ke terminal baterai negatif, dan terminal baterai positif terhadap trafo utama harus memiliki area cross sectional minimum $2 \mathrm{~mm} 2$ sehingga dapat meminimalkan drop tegangan. Rangkaian 12 inverter harus bekerja sekaligus, untuk penyesuaian pengaturan output frekuensi 50 $\mathrm{Hz}$ dengan menggunakan potensiometer. 


\subsection{Rangkaian Charger}

Sistem charger ini perubahan dari tegangan AC ke DC. Tegangan AC 220 Volt diturunkan menggunakan trafo step down untuk mencharger baterai 12 Volt DC melalui rangkaian charger (rectifier). Untuk jelasnya berikut ini disajikan blok diagram sistemnya.

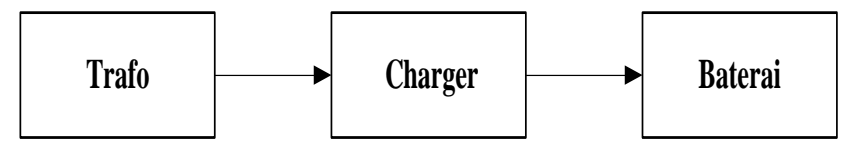

Gambar 8. Blok Diagram Charger

\subsection{Pembuatan Alat}

Pembuatan alat ini meliputi pembuatan skema rangkaian, pembuatan PCB, pengecekan komponen, pemasangan komponen serta pengukuran, pengujian dan perkabelan dalam pembuatan komponen agar aman dalam penggunaannya. Untuk pembuatan skema rangkaian dan PCB dilakukan dengan menggunakan bantuan software Orcad. Setelah PCB dibuat tahap selanjutnya adalah pemasangan dan penyolderan komponen pada PCB. Tahap tetakhir dari pembuatan perangkat keras yaitu pengukuran dan pengujian. Pengukuran dan pengujian merupakan tahapan penting untuk mengecek keseluruhan rangkaian yang telah dibuat. Apabila pada tahap ini didapat hasil sesuai spesifikasi dan tujuan yang telah ditentukan maka proses pembuatan selesai. Alur langkah pembuatan diatas dapat digambarkan sebagai berikut:

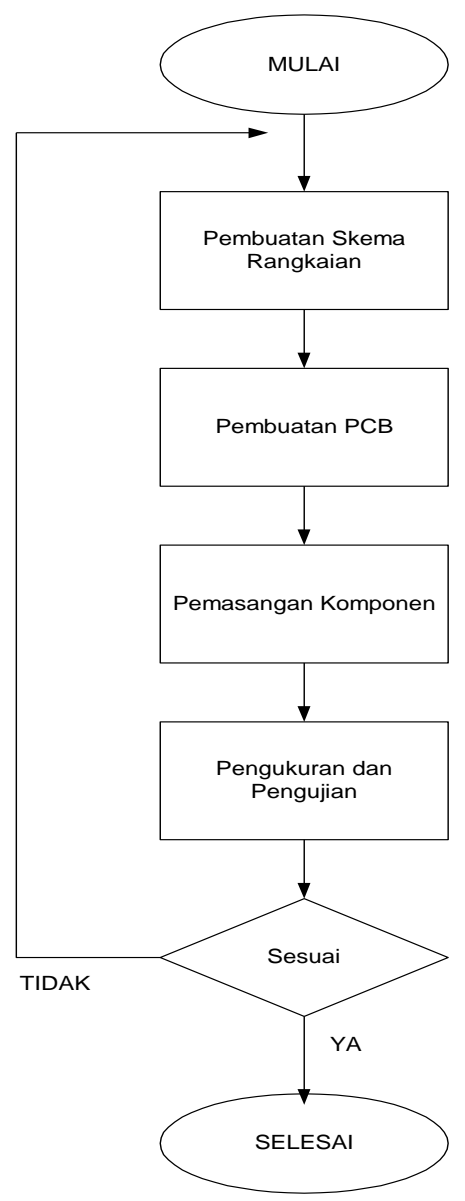

Gambar 9. Alur Pembuatan Alat 


\section{PENGUKURAN DAN PENGUJIAN ALAT}

\subsection{Pengukuran Rangkaian Rectifier}

Pengujian pertama dilakukan dengan mengukur arus dan tegangan yang keluar dari rectifier dengan menggunakan ampermeter dan voltmeter seperti gambar dibawah ini.

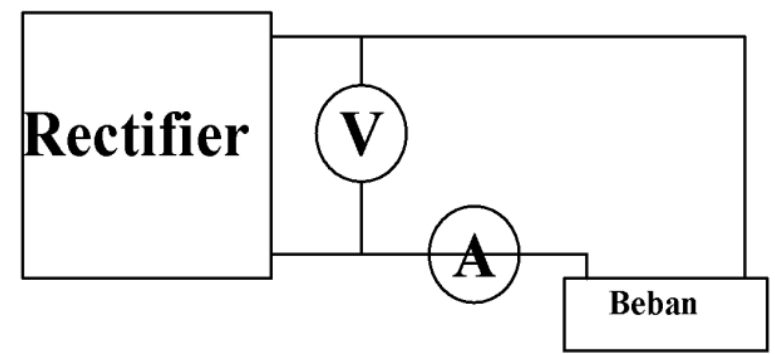

Gambar 10. Pengukuran Arus dan Tegangan pada Rectifier

Tabel 1. Pengukuran Tegangan dan Arus Keluaran Rectifier (Charger Baterai)

\begin{tabular}{|c|c|c|}
\hline Pengukuran ke & Tegangan Charger Baterai (V) & Arus Charger Baterai (I) \\
\hline I & $12,7 \mathrm{~V}$ & $11,1 \mathrm{~mA}$ \\
\hline II & $12,7 \mathrm{~V}$ & $11 \mathrm{~mA}$ \\
\hline III & $12,9 \mathrm{~V}$ & $10,9 \mathrm{~mA}$ \\
\hline IV & $12,9 \mathrm{~V}$ & $9,7 \mathrm{~mA}$ \\
\hline V & $12,8 \mathrm{~V}$ & $10,5 \mathrm{~mA}$ \\
\hline Rata-rata & $\mathbf{1 2 , 8} \mathbf{V}$ & $\mathbf{1 0 , 6 4} \mathrm{mA}$ \\
\hline
\end{tabular}

\subsection{Pengukuran Rangkaian Inverter}

Berikut ini adalah gambar dari sinyal yang diukur dengan menggunakan Oscilloscope dengan spesifikasi sebagai berikut :

Time/div $=25 \mathrm{~ms}$

Volt $/$ div $=2,5$ Volt



Gambar 11. Hasil Pengukuran Frekuensi dengan Menggunakan Oscilloscope

Rangkaian inverter yang dibuat terdiri dari IC 555, CMOS 4013, potensiometer, beberapa resistor, kapasitor non polar dan polar. Rangkaian ini yang akan memberikan tegangan pada transistor yang keluaran tegangannya digunakan sebagai inputan trafo step up. Berikut ini disajikan tabel hasil pengukuran rangkaian inverter yang telah dibuat, pada saat kondisi input dan output. 


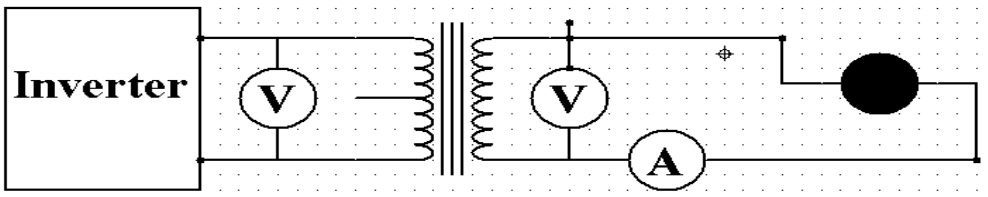

Gambar 12. Pengukuran Tegangan dan Arus Inverter

Tabel 2. Pengukuran Tegangan Input Trafo Step Up

\begin{tabular}{|c|c|}
\hline Pengukuran ke & Tegangan (V) \\
\hline I & 12,4 Volt \\
\hline II & 12,3 Volt \\
\hline III & 12,4 Volt \\
\hline IV & 12,3 Volt \\
\hline V & 12,4 Volt \\
\hline Rata-rata & $\mathbf{1 2 , 3 6}$ Volt \\
\hline
\end{tabular}

Tabel 3. Pengukuran Tegangan Output Trafo Step Up

\begin{tabular}{|c|c|}
\hline Pengukuran ke & Tegangan (V) \\
\hline I & 235 Volt \\
\hline II & 233 Volt \\
\hline III & 235 Volt \\
\hline IV & 235 Volt \\
\hline V & 233 Volt \\
\hline Rata-rata & $\mathbf{2 3 4 , 2}$ Volt \\
\hline
\end{tabular}

Tabel 4. Pengukuran Arus Output Trafo Step Up

\begin{tabular}{|c|c|c|}
\hline \multirow{2}{*}{ Pengukuran ke } & \multicolumn{2}{|c|}{ Arus (I) } \\
\cline { 2 - 3 } & Beban & Ukur \\
\hline I & $11,7 \mathrm{~K} \Omega$ & $20 \mathrm{~mA}$ \\
\hline II & $13,8 \mathrm{~K} \Omega$ & $17 \mathrm{~mA}$ \\
\hline III & $4,27 \mathrm{~K} \Omega$ & $55 \mathrm{~mA}$ \\
\hline IV & $9,03 \mathrm{~K} \Omega$ & $26 \mathrm{~mA}$ \\
\hline Rata-rata & $\mathbf{9 , 7} \mathbf{~} \boldsymbol{\Omega}$ & $\mathbf{2 9 , 5} \mathbf{~ m A}$ \\
\hline
\end{tabular}

\subsection{Pengujian Alat}

Pengujian merupakan langkah uji coba yang yang dilakukan terhadap alat yang telah dibuat supaya dapat diketahui kekuatan alat yang dibuat. Dan dalam pengujian inverter portable ini kita memakai beberapa daya lampu yang berbeda untuk melihat batas maximal daya yang dikeluarkan.

Tabel 5. Pengukuran Tegangan dan Arus Dengan Beban Yang Berbeda 


\begin{tabular}{|c|c|c|c|}
\hline \multirow{2}{*}{ Pengukuran ke } & \multicolumn{3}{|c|}{ Daya (Watt) } \\
\cline { 2 - 4 } & Beban Lampu & Tegangan (V) & Arus (I) \\
\hline I & 5 Watt & 235 Volt & $20 \mathrm{~mA}$ \\
\hline II & 11 Watt & 235 Volt & $46 \mathrm{~mA}$ \\
\hline III & 26 Watt & 235 Volt & $110 \mathrm{~mA}$ \\
\hline IV & 35 Watt & 235 Volt & $148 \mathrm{~mA}$ \\
\hline V & 75 Watt & 235 Volt & - \\
\hline
\end{tabular}

\section{KESIMPULAN DAN SARAN}

Setelah melakukan kajian terhadap dasar-dasar teori, merancang alat serta melakukan pengujian terhadap alat maka penulis dapat menyimpulkan inverter portable ini diperlukan rangkaian inverter dan rectifier yang sangat kecil tetapi mengeluarkan tegangan sesuai dengan peralatan elektronika dengan tegangan 220 - 240 volt dengan frekuensi $50 \mathrm{~Hz}$. Tetapi dalam pembuatan rangkaian ini secara manual maka hasilnya tidak sesuai dengan diharapkan ada bagian dari rangkaian yang tak bisa diperkecil yaitu trafo karena mempengaruhi keluaran tegangan yang diinginkan. Sehingga inverter portable agak berat.

Hardware dalam inverter portable ini terdiri dari input tegangan 220 volt yang kemudian masuk ke rangkaian rectifier untuk mencharger baterai aki 12 volt. Kemudian dari aki 12 volt menjadi input bagi rangkaian inverter yang akan menghasilkan tegangan 220 - 235 volt yang sebelumnya menggunakan trafo step up untuk menaikkan tegangannya yang melalui rangkaian inverter yang terdiri dari IC 555, transistor darlington, potensiometer yang sangat penting untuk mengatur frekuensi agar tetap $50 \mathrm{~Hz}$. Kapasitas baterai yang digunakan adalah 3,2 Ah dengan beda potensial 12 Volt. Maka baterai tersebut memiliki energi 138,24 K joule. Kemudian inverter portable dapat digunakan untuk lampu, charger handphone, netbook dan dapat dibuat dengan harga yang cukup ekonomis.

Untuk penelitian selanjutnya akan terfokus pada trafo frekuensi untuk mengurangi bobot inverter portable agar lebih ringan.

\section{DAFTAR PUSTAKA}

[1] O. Bishop, Dasar-dasar Elektronika. Jakarta: Penerbit Erlangga, 2002.

[2] P. Frank D, Elektronika Industri. Yogyakarta: Andi, 1996.

[3] Sutrisno, Elektronika Teori dan Penerapan 1 dan 2. Bandung: ITB.

[4] K. Jaja, "Modul Elektronika Industri," Bandung, 2010.

[5] Universitas Pendidikan Indonesia, Pedoman Penulisan Karya Ilmiah. Bandung: UPI, 2007.

[6] W. Lingga Suwastono, Pembuatan Skematik Rangkaian Elektronika dan Layout PCB Menggunkan OrCAd release 9.1. Yogyakarta: Andi, 2006.

[7] M. A Paul, Prinsip-prinsip Elektronika. Jakarta: Penerbit Erlangga, 1984.

[8] M. A Paul, Prinsip-prinsip Elektronika. Jakarta: Salemba Teknik, 2004.

[9] T. Mike, Rangkaian Elektronik Prinsip dan Aplikasi. Jakarta: Erlangga, 2002.

[10] I. KF, Teknik Digital. Yogyakarta: Penerbit Andi, 1996.

[11] W. Lukas, Teknik Digital, Mikroprosesor, dan Mikrokomputer. Bandung: Informatika, 2010. 